\title{
PAPER
}

\section{Physical analysis of an electric resistor heating}

To cite this article: J E M Perea Martins 2018 Phys. Educ. 53035023

View the article online for updates and enhancements.

\section{IOP ebooks}

Bringing you innovative digital publishing with leading voices

to create your essential collection of books in STEM research.

Start exploring the collection - download the first chapter of every title for free. 


\title{
Physical analysis of an electric resistor heating
}

\author{
J E M Perea Martins \\ Computer Science Department, School of Sciences (FC), São Paulo State University \\ (UNESP), 17033-360, Bauru-SP, Brazil \\ E-mail: perea@fc.unesp.br
}

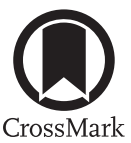

\begin{abstract}
This work describes a simple experiment to measure the resistor temperature as a function of the applied power and proves that it is an efficient way to introduce some important physical concepts in classroom, including the Joule's first law, hot-spot temperature, thermal resistance, thermal dissipation constant, time constant and the Newton's law of cooling.
\end{abstract}

\section{Introduction}

An electric resistor limits the electric current magnitude due to the conversion of electrical energy to heat, which consequently warms the resistor. It occurs according to the Joule's first law principle, which defines the phenomenon of heat generation when electric current passes through an element and is an important principle that can be associated with the everyday life through appliances such as bread toasters, clothes iron and hair dryers. Therefore, there is a relation between generated heat and electrical energy expressed as:

$$
Q=I^{2} R t \text {. }
$$

Where: $Q$ is the generated heat $(\mathrm{J})$

$I$ is the current through the resistor (A)

$R$ is the resistor value $(\Omega)$

$t$ is the period (s)

The product $I^{2} R$ is the dissipated power $(P)$, whose unit is watts and represents the rate at which energy is delivered for a period. Therefore, $1 \mathrm{~W}$ equals $1 \mathrm{~J} \mathrm{~s}^{-1}$ and equation (1) can be rewritten as:

$$
Q=P t .
$$

The power depends on the applied voltage $(V)$ and both are related as:

$$
V=\sqrt{P R}
$$

In this context, this work considers important two observations in classroom:

1. Despite equation (2) continuity over time, the resistor heating is not infinite because part of the heat is lost to the environment (surroundings) and the resistor tends to a thermal stabilization where the added energy equals the lost energy. Therefore, the resistor temperature increases for a period and then stabilizes at about a fixed value.

2. There are factors such as the resistor mass, size, shape, material, and ambient temperature that do not appear in basic equations but can influence directly the resistor heating.

These observations are also important to make students aware the real applications of general mathematical models should consider there may be exceptional cases where inexplicit physical factors can influence the expected system behaviour and experiments results.

\section{Methodology}

Figure 1 shows the experiment mounting for the resistor temperature measurement, which requires only a resistor, a breadboard, an adjustable power source and a thermometer with data logger. 


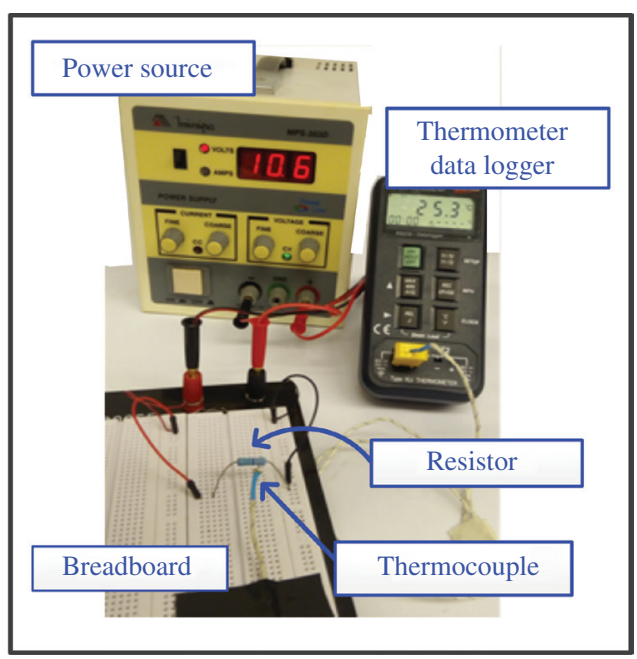

Figure 1. The experiment mounting.

Firstly, the applied power $(P)$ is defined and so the associated voltage is computed according to equation (3). The applied power cannot be larger than a resistor parameter called power rating $\left(P_{\mathrm{r}}\right)$ that determines the maximum amount of power that it can dissipate without damage. The power $P$ can also be presented as a percentage of $P_{\mathrm{r}}$, which is called rated power $\left(P_{\mathrm{p}}\right)$.

Subsequently, the power source is set and connected to the resistor whose temperature is measured with a thermocouple that has small measurement junction and therefore allows the measurement on a precise point of the resistor surface.

This work experiments were accomplished with a $56 \Omega$ film resistor with $P_{\mathrm{r}}$ of $2 \mathrm{~W}$, in still air and ambient temperature at about $23{ }^{\circ} \mathrm{C}$. Therefore, all resistor temperature values in the next sections refer exclusively to this specific resistor.

A preventive consideration in classroom is about the resistor temperature that can reach hundreds of degrees in many cases. Therefore, special cares should be taken in educational laboratories to avoid the direct body contact (usually fingers) with very hot resistors.

\section{The resistor temperature measurement}

This experiment verifies the resistor temperature variation as a function of the applied power, which is this article essence. Figure 3 shows

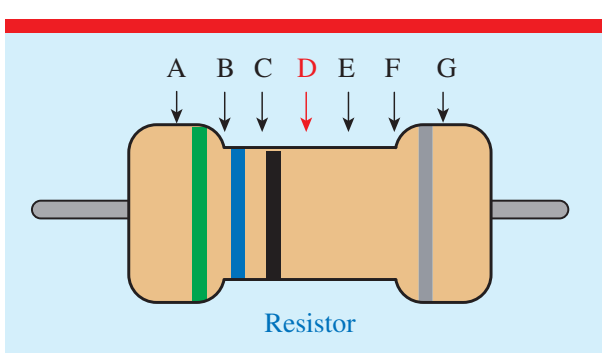

Figure 2. Points of temperature measurement.

Table 1. The resistor surface temperature.

\begin{tabular}{lrrrrrrr}
\hline & \multicolumn{6}{c}{ Temperature $\left({ }^{\circ} \mathrm{C}\right)$ on the points } \\
\cline { 2 - 8 }$P($ W $)$ & A & \multicolumn{1}{c}{ B } & \multicolumn{1}{c}{ C } & \multicolumn{1}{c}{ D } & \multicolumn{1}{c}{ E } & F & G \\
\hline 2.0 & 102 & 119 & 120 & 122 & 119 & 117 & 99 \\
0.5 & 49 & 51 & 51 & 52 & 51 & 50 & 48 \\
\hline
\end{tabular}

the experiment results and it is also the basis to introduce the physical concepts in the subsequent sections.

The first step is to verify the point where the thermocouple will be fixed on the resistor surface that can present a non-uniform temperature variation due to manufacturing process inaccuracies and the resistor leads (terminals) influence that act as coolers and decrease the ends temperatures. The thermocouple must be fixed on the point of the highest resistor surface temperature that is called hot-spot temperature and usually is on its centretop. Figure 2 shows the points verified in this work.

Table 1 shows the temperatures on each point, for applied powers of $2 \mathrm{~W}$ and $0.5 \mathrm{~W}$, generated with voltages of $10.6 \mathrm{~V}$ and $5.3 \mathrm{~V}$. The hotspot temperature is on the point ' $\mathrm{D}$ ', which is so defined for measurements. In exceptional cases, this experiment is accomplished with the resistor suspended by its terminals in the air, without the breadboard, avoiding the breadboard heating and its influence on the measurement accuracy.

Subsequently, the experiment to verify the resistor heating and cooling over time for different applied powers is performed as:

1. The thermocouple is fixed on the hot-spot point ' $\mathrm{D}$ '

2. The data logger is started

3. The power source previously set to a specific value is turned on

4. After a period, the power source is turned off. 
Physical analysis of an electric resistor heating

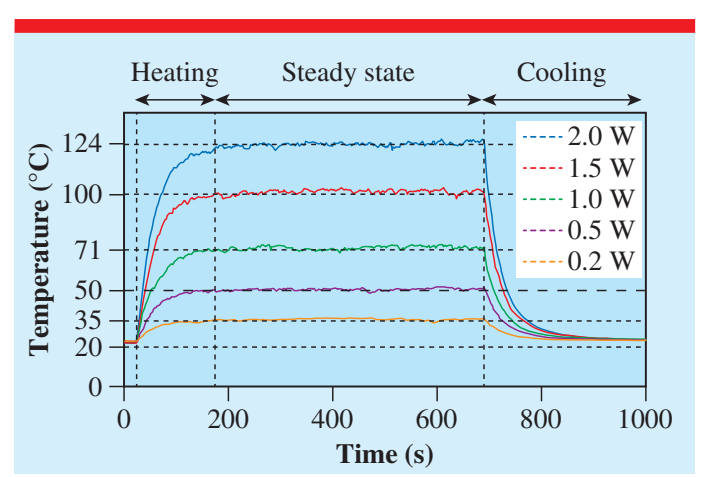

Figure 3. The resistor temperature variation.

Figure 3 shows the temperature variation for five applied powers, where each curve presents the three stages:

1. Heating: It starts when the power source is turned on and ends when the temperature stabilizes at about a higher value.

2. Steady state: The 'steady state' indicates a temperature stabilization, where it becomes constant or has only small variations at about a value. In this context, it is interesting to remind students that 'thermal stabilization' is a concept different of 'thermal equilibrium' that represents the heat transference from a hotter to a colder object when both are in direct contact and temperatures tend to the same value.

3. Cooling: It starts when the power source is turned off and ends when the resistor temperature decreases and reaches the ambient temperature.

This experiment results depend on several factors such as voltage accuracy, power oscillations, sensor positioning, ambient temperature, and air flow. Therefore, small results variation may occur for each new experiment accomplishment.

\section{Physical concepts}

This section proposes the analysis of some selected physical concepts that can be directly associated with the resistor temperature variation and allow an interaction between theory and practice in classroom. Note that, all the concepts explained below are associated with the figure 3 .

\subsection{Mathematical models}

Figure 4 emphasize the physical heating and cooling curves extracted directly from figure 3, which can be represented by standard mathematical models. The cooling is an exponential decay expressed as equation (4), and the heating fellows a model called bounded exponential growth or saturating exponential growth that expressed as equation (5) and is different of the traditional natural exponential growth expressed as equation (6).

$$
\begin{aligned}
& y(t)=a+(b-a) \mathrm{e}^{-k t} \\
& y(t)=a+(b-a)\left(1-\mathrm{e}^{-k t}\right) \\
& y(t)=a+\mathrm{e}^{k t} .
\end{aligned}
$$

Where:

- $a$ is the lowest $y$ value

- $b$ is the highest $y$ value

- $k$ is the $y$ variation rate

- $t$ is the time

The exponential variations represent the behaviour of several phenomena in areas as physics, biology, engineering, etc. Therefore, the resistor heating and cooling are only specific cases among several other phenomena in nature whose variation fellows these trends. This work suggests an additional homework that students describe examples of phenomena with exponential variation, in different areas. It can be a type of guided discovery task where students can use their classroom learning in other realistic contexts.

\subsection{Thermal resistance}

The figure 3 steady state temperature $\left(T_{\mathrm{s}}\right)$ allows the thermal resistance $\left(R_{\theta}\right)$ computation, which is a general principle intuitively associated with the opposition to the heat flow through an element. It is computed as the ratio between the element temperature variations $(\Delta T)$ to the heat quantity $(Q)$ through it. The unit is $\mathrm{K} \mathrm{W}^{-1}[1]$, however remember that $\mathrm{K} \mathrm{W}^{-1}$ and ${ }^{\circ} \mathrm{C} \mathrm{W}^{-1}$ are interchangeable.

$$
R_{\theta}=\frac{\Delta T}{Q} .
$$




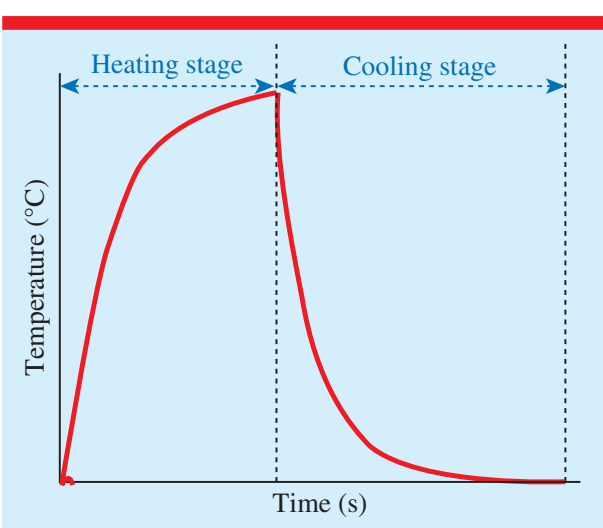

Figure 4. Heating and cooling stages.

In the resistor context, the BIPM thermometry committee $[2,3]$ uses the relation $1 \mathrm{~W}=1 \mathrm{~J}$ $\mathrm{s}^{-1}$ to detail $R_{\theta}$ as $[3,4]$ :

$$
\begin{aligned}
R_{\theta} & =\frac{\Delta T}{P} \\
\Delta T & =T_{\mathrm{s}}-T_{\mathrm{a}} .
\end{aligned}
$$

Where: $T_{\mathrm{a}}$ is the ambient temperature

Based on the figure 3 curve for $P=2 \mathrm{~W}$, it is computed as:

$$
R_{\theta}=\frac{(124-22.6)^{\circ} \mathrm{C}}{2 W}=50.7^{\circ} \mathrm{CW}^{-1} .
$$

Small $R_{\theta}$ variations can occur for the computation with different applied powers due to measurement inaccuracies.

\subsection{Thermal resistance contexts}

In fact, the thermal resistance concept is widely used in several areas such as physics, chemistry, civil engineering, electronics, etc. Therefore, it includes numerous particularities that have historically motivated several discussions $[5,6]$.

It is relevant to explain in classroom that resistor manufacturers typically use the term 'thermal resistance' $(\theta)$ to express the relation between the applied power and the ambient temperature. Figure 5 shows a graph called Resistor Derating Curve that represents this relation.

The resistor temperature is the addition of its initial temperature (ambient temperature) and a temperature value derived from the Joule's affect. Therefore, the addition must be smaller than a maximum resistor operational limit to avoid damages.
Top is the maximum ambient temperature where the resistor can operate with $P_{\mathrm{p}}$ at $100 \%$. When the ambient temperature becomes greater than Top, the $P_{\mathrm{r}}$ value must be gradually decreased. When the ambient temperature reaches $T_{\max }$, the applied power becomes zero. In this context, manufactures express $\theta$ as:

$$
\theta=\left(T_{\max }-T o p\right) / P_{r} .
$$

For example, a traditional carbon film resistor with $P_{\mathrm{r}}$ of $1 / 2 \mathrm{~W}$ has typical Top and $T_{\max }$ values at about $70{ }^{\circ} \mathrm{C}$ and $150{ }^{\circ} \mathrm{C}$. In this case, $\theta$ is computed as $(150-70) / 0.5$ and equals 160 ${ }^{\circ} \mathrm{C} \mathrm{W}^{-1}$ or $0.16{ }^{\circ} \mathrm{C} \mathrm{mW}{ }^{-1}$. Therefore, for each interval of $0.16{ }^{\circ} \mathrm{C}$ above $70{ }^{\circ} \mathrm{C}$, the maximum applied power is decreased at $1 \mathrm{~mW}$.

Another example is associated with fields that include the concept of heat flow per unit area (A) and express $R_{\theta}$ according to equation (11), whose unit is $\mathrm{m}^{2} \mathrm{~K} \mathrm{~W}^{-1}$.

$$
R_{\theta}=A \frac{\Delta T}{Q} .
$$

An additional example is the clothing thermal insulation, which is easily related to the everyday life and presents two forms called tog and clo, defined as:

$$
\begin{aligned}
& 1 \text { clo }=0.155 \mathrm{~m}^{2} \mathrm{~K} \mathrm{~W}^{-1} \\
& 1 \text { tog }=0.1 \mathrm{~m}^{2} \mathrm{~K} \mathrm{~W}^{-1} \text {. }
\end{aligned}
$$

The clothing insulation is an important applied physics subject with high relevance for industry and human health. For a practical approach, 1 clo represents the insulation required to maintain a person in comfort sitting at rest in a room at $21^{\circ} \mathrm{C}$, which can be provided by a typical business suit. For freezing winter nights, the textile industry recommends duvets with a minimum insulation at about 13 togs. At this point it is interesting to remind students clothes do not generate heat and therefore do not heat the body. They act only as an insulating that limits the heat transference from the body to the colder surroundings.

Note that, there are different mathematical and conceptual approaches for the physical idea of thermal resistance, which can vary according to the context. It is an important observation to show students the accurate definition of a physical phenomenon and its respective unit is a classical problem in physics, which can require the analyses of complex details and different 


\section{Physical analysis of an electric resistor heating}

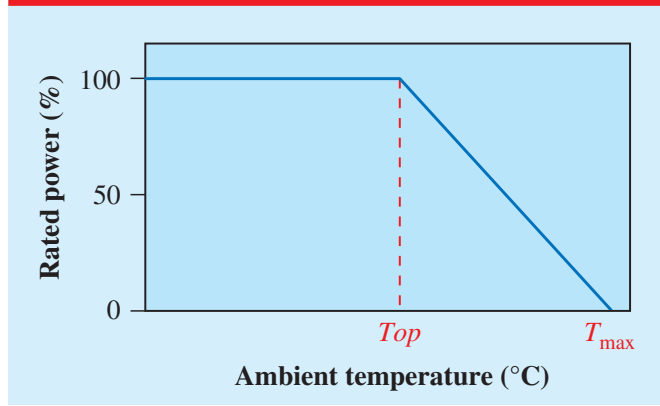

Figure 5. The resistor derating curve.

specificities. In fact, it is a so relevant subject that the International System of Units (SI) itself is still in evolution and remains as the focus of current reflections [7].

\subsection{Thermal dissipation constant}

The $T_{\mathrm{s}}$ and $T_{\mathrm{a}}$ values extracted from figure 3 also allows the Thermal Dissipation Constant $(\delta)$ computation, which is the amount of applied power required to raise the resistor temperature by $1{ }^{\circ} \mathrm{C}$ when it is originally in equilibrium with its medium [2], and whose unit is $\mathrm{W}^{\circ} \mathrm{C}^{-1}$

$$
\delta=\frac{P_{r}}{\Delta T} .
$$

It is an important parameter to estimate the error associated with resistive temperature sensors (thermistors) that should detect only the exact surrounding temperature but it is added with the thermistor temperature that depend on the Joule's effect and represents a measurement error. In this work, it was computed as:

$$
\delta=\frac{2 W}{\left(124^{\circ} \mathrm{C}-22.6^{\circ} \mathrm{C}\right)}=19.7 \mathrm{~mW}^{\circ} \mathrm{C}^{-1} \text {. }
$$

\subsection{Thermal time constant}

The figure 3 cooling stage allows the time constant $\left(\tau_{\mathrm{C}}\right)$ computation, which is formally defined as the time required for a parameter variation of $63.2 \%$ between an initial and a final value. Besides the resistor context, it can also be associated with several other natural phenomena.

For the resistor $\tau_{\mathrm{C}}$ measurement, its temperature must be increased to $85{ }^{\circ} \mathrm{C}$ with a specific

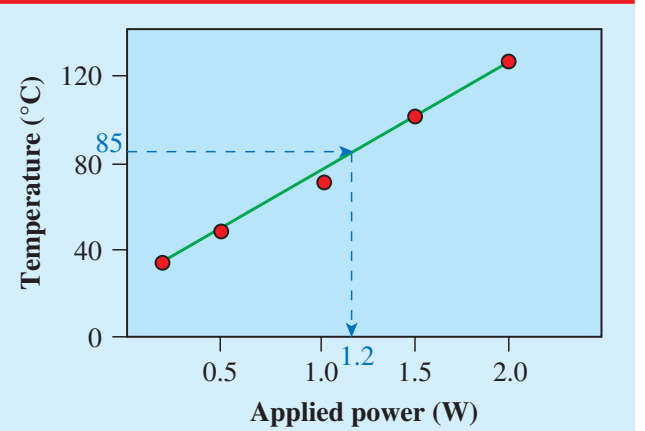

Figure 6. Applied power and temperature relation.

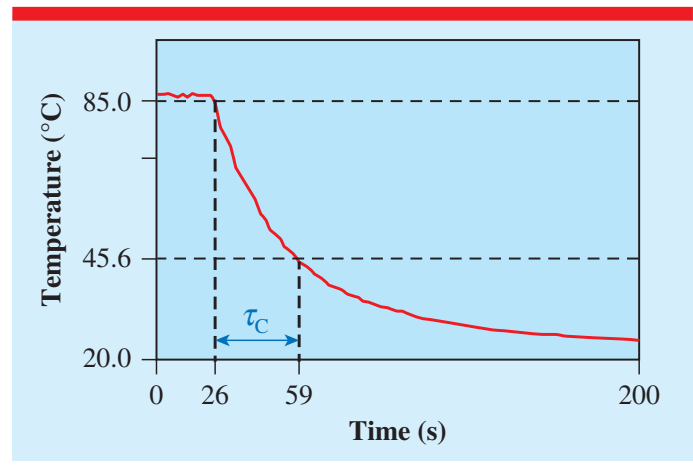

Figure 7. The time constant $\left(\tau_{\mathrm{C}}\right)$.

applied power. After a period of stabilization, it is turned off and time required decreasing $63.2 \%$ of this temperature is measured. The final temperature variation range $\left(T_{\mathrm{w}}\right)$ depends on the $85^{\circ} \mathrm{C}$ and the ambient temperature $\left(T_{\mathrm{a}}\right)$, and is computed as:

$$
T_{\mathrm{w}}=85-\left(85-T_{\mathrm{a}}\right) * 0.632
$$

$\tau_{\mathrm{C}}$ is important to indicate the resistor temperature variation speed. In the case of a thermistor, it indicates the speed at which the sensor can detect temperature variations and the ideal is a thermistor as fast as possible.

Figure 6 shows the relation between applied power and the resistor temperature, whose values were extracted from figure 3. It defines an applied power of $1.2 \mathrm{~W}(8.3 \mathrm{~V})$ heats the resistor at about $85^{\circ} \mathrm{C}$.

In this work, $T_{\mathrm{w}}$ was computed at $45.6{ }^{\circ} \mathrm{C}$ and figure 7 shows the time $\left(\tau_{\mathrm{C}}\right)$ for a variation from $85^{\circ} \mathrm{C}$ to $45.6{ }^{\circ} \mathrm{C}$ that was timed in $33 \mathrm{~s}$ in still air, for the present case. 


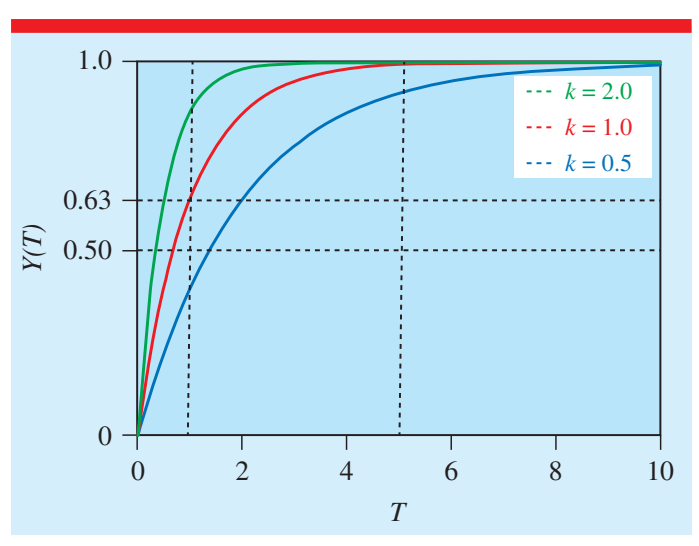

Figure 8. Bounded exponential growth for different $k$ values.

\subsection{The variation range}

A typical question in classroom is about the $63.2 \%$ origin, which can be explained with the mathematical association of $\tau_{\mathrm{C}}$ and $k$. Figure 8 shows the bounded exponential growth for different $k$ values (variation rate), where students can obverse intuitively that $63.2 \%$ represents a linear approximation where the curves (phenomena) present a more uniform behaviour.

For a mathematical approach, equations (7) and (8) can be rewritten replacing $k$ with $\left(1 / \tau_{\mathrm{C}}\right)$, as:

$$
\begin{gathered}
y(t)=a+(b-a) \mathrm{e}^{-t / \tau c} \\
y(t)=a+(b-a)\left(1-\mathrm{e}^{-t / \tau c}\right) .
\end{gathered}
$$

When $a=0, b=1$ and $k=1\left(\tau_{\mathrm{C}}=1\right)$ equation (18) reduces to the natural bounded exponential growth expressed as $y(t)=1-\mathrm{e}^{-t}$ and for the first-time interval $(t=1)$ it is computed as:

$$
y(1)=1-\mathrm{e}^{-1}=1-\frac{1}{\mathrm{e}}=0.632 .
$$

It proves that $63.2 \%$ represents the variation of the first-time interval when $\tau_{\mathrm{C}}=1$. Based on the same principle, the first time for the natural exponential decaying from equation (17) is computed as:

$$
y(1)=\mathrm{e}^{-1}=\frac{1}{\mathrm{e}}=0.368 .
$$

Equation (20) indicates $y(1)$ is at $36.8 \%$ of the decaying final interval, which consequently is at $(1-0.368)$ or 0.632 from its beginning.

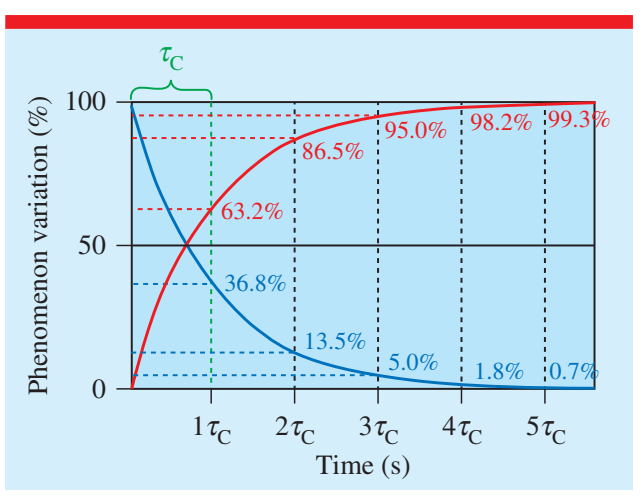

Figure 9. Percentage variation as a function of $\tau_{\mathrm{C}}$.

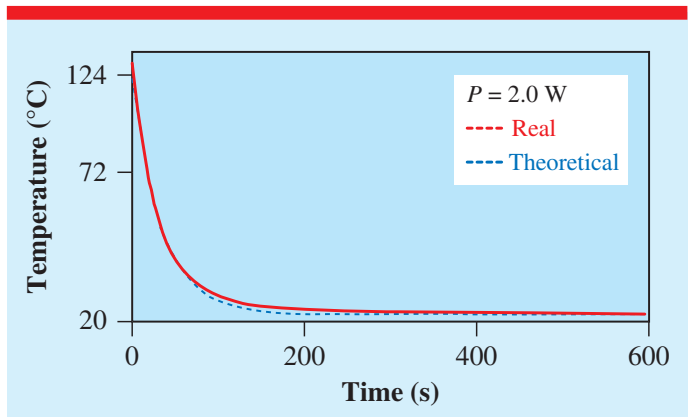

Figure 10. Resistor cooling from $124{ }^{\circ} \mathrm{C}$.

Figure 9 exemplifies the phenomenon percentage variation as a function of $\tau_{\mathrm{C}}$ for both curves.

\subsection{Newton's law of cooling}

The figure 3 cooling stages can also be associated with Newton's law of cooling that computes the object temperature in a cooling process over time. It is expressed as equation (21), which equals equation (7) because it is a typical case of exponential decaying.

$$
T(t)=T_{\mathrm{a}}+\left(T_{\mathrm{h}}-T_{\mathrm{a}}\right) \mathrm{e}^{-k t} .
$$

Where: $T(t)$ is the object temperature $T$ at time $t$.

$T_{\mathrm{h}}$ is the hot object temperature at initial time.

Equation (22) computes the $k$ value, which requires the previous measurement of $T_{\mathrm{a}}, T_{\mathrm{h}}$ and $T(t)$.

$$
k=-\ln \left(\frac{T(t)-T_{\mathrm{a}}}{T_{\mathrm{h}}-T_{\mathrm{a}}}\right) \frac{1}{t} .
$$


Physical analysis of an electric resistor heating

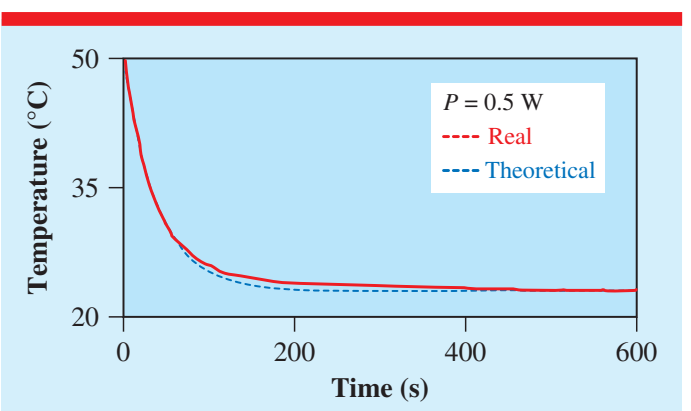

Figure 11. Resistor cooling from $50{ }^{\circ} \mathrm{C}$.

Figure 10 shows the real cooling curve (red) extracted from figure 3 and the theoretical (blue) computed with equation (21), for $P$ of $2 \mathrm{~W}$. Figure 11 shows the curves for an applied power of $0.5 \mathrm{~W}$.

Figures 10 and 11 show the Newton's law of cooling provides a very good approximation, but theoretical and real cooling curves do not fit perfectly due to the influence of physical parameters as heat transfer modes, object temperature, surroundings interactions and experiment system mounting. It reinforces the section 1 explanation that inexplicit physical factors can influence directly the system behaviour.

Several works $[8,9]$ detail historical reviews on this law and other subsequent correlated studies, demonstrating that an accurate mathematical object cooling representation is a complex scientific question. They indicate that Newton was interested in defining a thermometric scale where the cooling process was concerned only as a general property of heat and presented without mathematical formalism. This historical analysis is an efficient way to demonstrate in classroom the study of an apparent simple physical problem can involve several secondary complex factors.

\section{Conclusion}

The proposed experiment proved the resistor temperature can be measured in educational laboratories and its analysis are a concrete way to teach several physical concepts that were conceptually and numerically presented in this work and support an educational scenario that interacts directly theories and practices.

Received 15 January 2018

Accepted for publication 12 February 2018

https://doi.org/10.1088/1361-6552/aaae80

\section{References}

[1] Çengel Y A 2003 Heat Transfer: A Practical Approach (New York: McGraw-Hill)

[2] White D R et al 2014 Guide on Secondary Thermometry: Thermistor Thermometry (Paris: Bureau International des Poids et Mesures)

[3] ASTM (American Society for Testing and Materials) 2017 Standard Terminology Relating to Thermal Insulation - ASTM C16817 West Conshohocken, PA, USA (https://doi. org/10.1520/C0168-17)

[4] JEDEC Standard JESD51-13 (Solid State Technology Association) 2009 Glossary of Thermal Measurement Terms and Definitions, Arlington, VA, USA (www.jedec.org/ standards-documents/docs/jesd-51-13) (Accessed: November 2017)

[5] Cena K and Clark J A 1978 Thermal resistance units J. Therm. Biol. 3 173-4

[6] Lasance C J M 1997 Thermal resistance: an oxymoron? Electron. Cooling Mag. 2 (www.electronics-cooling.com/1997/05/ thermal-resistance-an-oxymoron) (Accessed: November 2017)

[7] Knotts S, Mohr P J and Phillips W D 2017 An introduction to the new SI Phys. Teach. 55 16-21

[8] Vollmer M 2009 Newton's law of cooling revisited Eur. J. Phys. 30 1063-84

[9] Besson U 2012 The history of the cooling law: when the search for simplicity can be an obstacle Sci. Educ. 21 1085-110

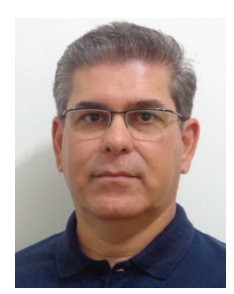

J. E. M. Perea Martins is professor of computer science at the Sao Paulo State University (UNESP), in Brazil. He received his bachelor degree in computer science from UNESP and his master and $\mathrm{PhD}$ degrees in physics from the University of São Paulo (USP) in Brazil. Currently, his research interest areas include electronic instrumentation, microcontrollers, computer simulation, and physics education. 